\title{
Wireless Displaying Device
}

\author{
Ankit Pandit, Ashish Chauhan, Monika Verma
}

\begin{abstract}
The present invention relates to wireless displaying device for displaying a large number of information within a single display device. The main aim of this paper is to develop a cost-effective device that is capable of storing the large no. of information and control the data wirelessly. The information displayed on the device can be changed by sending a message through a mobile phone directly to the displaying device wirelessly.
\end{abstract}

\section{Keywords- GSM, microcontroller, SIM, Displaying unit.}

\section{INTRODUCTION}

In today's modern world most of the schools, colleges and offices have display board for displaying different kind of useful information. At present, everyone is using manually operated notice board. These boards are manually operated and user cannot display multiple information at a time as it as limited space [1]. The conventional method of writing on paper and sticking it on notice board so that other can read the important information is inclined to errors. Sometimes the person delivering the information could have wrong information and for correcting that information the user has to change the whole paper and write the information again [5]. This process of reading and writing on notice board is time consuming and takes much human efforts to correct it. With passage of time as the technology get advances, effective, economically affordable and the need of extremely creative output becomes a complete requirement, which attract the customer towards the use of smart automation system. The use of manmade automation system not only allow the user to use the appliances smartly but also eliminates the human error [2]. Therefore, With the new electronics-based wireless displaying device we are able to solve many problems related to human errors, multiple data storage and cost effectiveness[3], [4]. This novel device can be installed in offices, schools or colleges and provide unique method of eliminating the use of paper for displaying the information in the notice board. In this project the user has to simply send an SMS from his/her mobile phone with the information that is to be displayed, after sending the message the displaying unit starts to show the send information remotely. If the user wants any change in the information displaying on the notice board then he/she could send the message again and correct the changes successfully without much efforts. The main advantage of this device is that it eliminates the use of paper which is produced by cutting lots of trees.

Revised Manuscript Received on 14 September, 2019.

Ankit Pandit, Department of Electronics \& Communication Engineering, Rabindranath Tagore University, Bhopal, MadhyaPradesh, India.

Dr. Ashish Chauhan, Department of Electronics \& Communication Engineering, Rabindranath Tagore University, Bhopal, MadhyaPradesh, India.

Monika Verma, Department of Electronics \& Communication Engineering, Rabindranath Tagore University, Bhopal, MadhyaPradesh, India.

\section{LITERATURE REVIEW}

Conventionally, in schools and colleges if a person wants to deliver some kinds of news or information, he/she would have to write down on paper and stick it on the notice board. This method of delivering news and information on the notice board requires a lot of human effort and if in the delivered information any mistake or error is found then the writing person has to remove whole of the pages from notice board and has to write it again with amendment. This require a lot of time and have a wastage of paper. Therefore, various displaying devices are developed in the past which are installed in shopping malls, railway station, school or colleges for showing information. These displaying device are based on static messages, in which a fixed message is displayed and another coding is used to develop for displaying next message [5],[6],[7]. Hence these devices are not suitable for multiple message displaying therefore these devices are neglected.

\section{WORKING OF WIRELESS DISPLAYING DEVICE \& RESULTS}

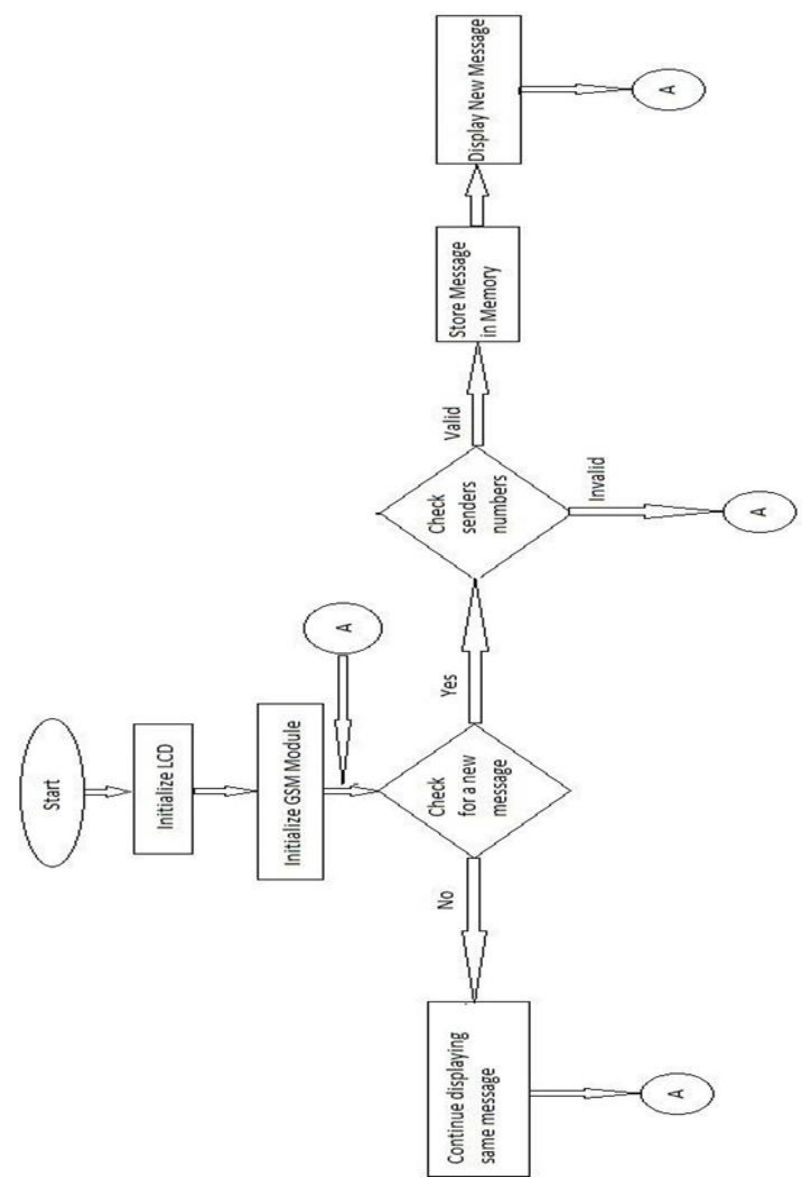

Fig.1 Flowchart of Displaying Device

Published By: 


\section{Mobile phone}

The mobile phone required in this project is just for sending the messages to the GSM module. The mobile phone is not necessary to be a smart phone, it could be a simple mobile that has a capability of sending and receiving the messages through SMS. The mobile phone can be used to change the information which is being displayed on the displaying unit.

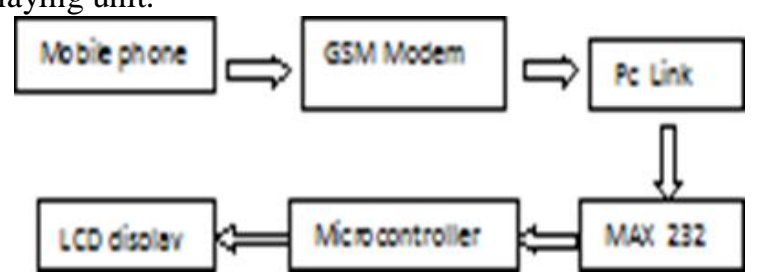

Fig.2 Block diagram of displaying device

\section{GSM Modem}

The mobile transmitted message is received directly by the GSM modem to further transmit it to the pc link. The GSM modem is basically act as a message receiving unit that receive the messages from the mobile phone wirelessly [8]. It plays an important role in communication system for sending and receiving messages without any physical connections.

\section{PC Link}

The pc link act as a gateway for transmitting the signal received from GSM modem to the microcontroller through the MAX 232. It is an online server for transmitting the information into the correct path without interrupting it.

\section{MAX 232}

It is an integrated circuit that convert transmission signal (TX), receiving signal (RX), Request to Send / Clear to Send (RTS/CTS) signals accordingly. MAX 232 is a dual transmitter and dual receiver that uses $12 \mathrm{v}$ dc supply for its operation. MAX232 is directly linked with the microcontroller for receiving the signals from GSM modem and sending it to microcontroller by converting it accordingly.

\section{Microcontroller}

An 8-bit microcontroller is connected to the displaying unit for controlling the input signal sends by the user and transmitting it to the display unit for displaying the information. Through the microcontroller multiple messages can be displayed on the LCD screen. For displaying multiple messages, a specific type of coding is done in the microcontroller.

\section{LCD Display}

Displaying unit is basically 20x4 cm LCD screen which consist of large number of LEDs array connected in series. Its main purpose is to display the messages send by

Fig.3 shows the complete specification of wireless displaying unit is shown below. It comprises of all the component along with its rating. microcontroller.

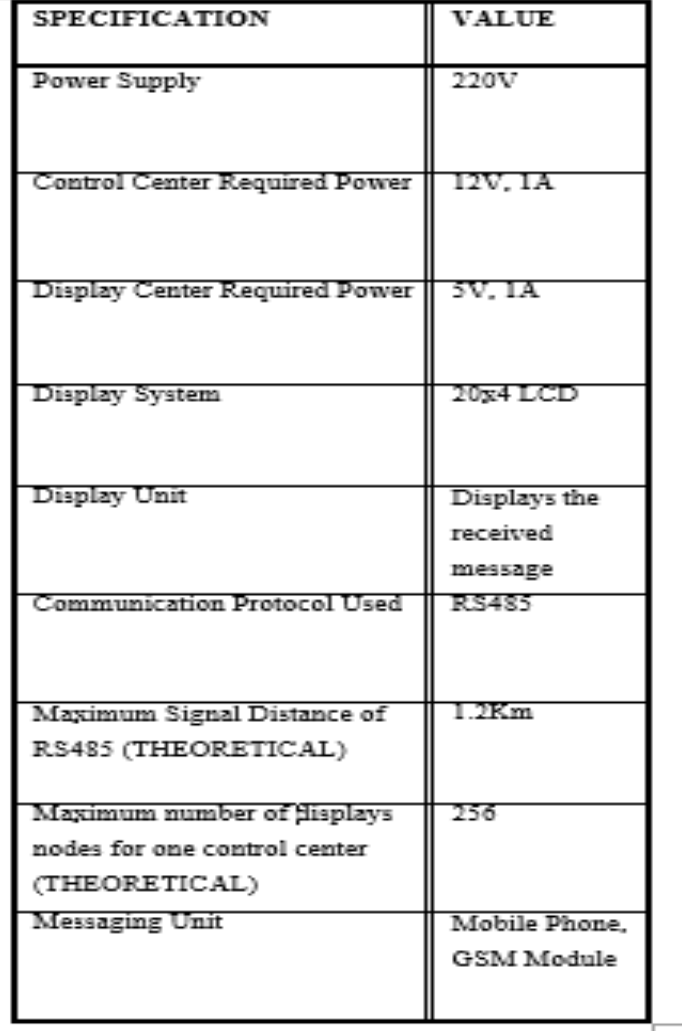

Fig.3 Complete Specification

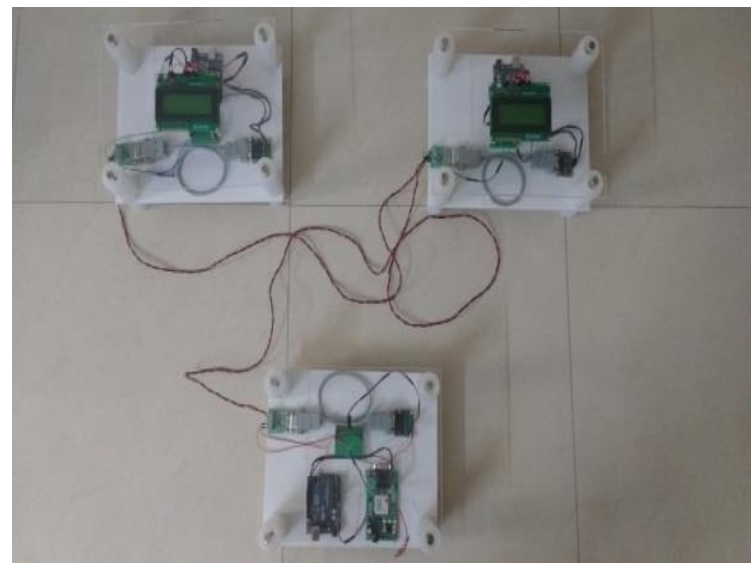

Fig.4 Hardware Demonstration

The wireless based displaying unit is demonstrated with a capability of displaying messages send by user through the mobile phone.

\section{CONCLUSION}

The wireless displaying device is successfully designed and replaced by the conventional electronic boards which uses only static messages displaying system. For displaying multiple messages. Firstly, the user sends a message that is to be display by mobile phone to GSM module and the GSM module transmit the message wirelessly to microcontroller. And finally, the microcontroller connected with the LED display unit transmit the information to the LEDs for delivering the information. This device is very much economical and has a fast time response.

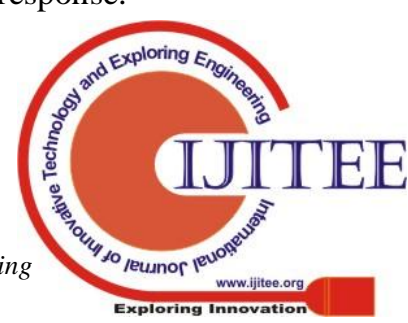




\section{REFERENCES}

1. D. Looseley, "Notice-board," French Cult. Stud., 1993.

2. D. B. Kaber, J. M. Riley, K.-W. Tan, and M. R. Endsley, "On the Design of Adaptive Automation for Complex Systems," Int. J. Cogn. Ergon., 2004.

3. F. Kamdar, A. Malhotra, and P. Mahadik, "Display Message on Notice Board using GSM," Research India Publications-Advance in Electronic and Electric Engineering, 2013.

4. R. Parasuraman, "Designing automation for human use: Empirical studies and quantitative models," Ergonomics, 2000.

5. P. K. M. Robin Raju, Praful Mishra, Mrudula Maghade, "Smart Board," Int. J. Sci. Res. Comput. Sci. Eng. Inf. Technol., 2018.

6. D. K. Sharma, V. Tiwari, K. Kumar, B. A. Botre, and S. A. Akbar, "Small and medium range wireless electronic notice board using Bluetooth and ZigBee," in 12th IEEE International Conference Electronics, Energy, Environment, Communication, Computer, Control: (E3C3), INDICON 2015, 2016.

7. M. Rama Krishna, N. Ravishankar, P. Venkata Brahmam, I. V. Sekhar, P. Chenna, and K. Rao, "GSM Based Rewritable Digital Notice Board," Int. J. Mod. Trends Sci. Technol., 2018.

8. A. Pramanik, Rishikesh, V. Nagar, S. Dwivedi, and B. Choudhury, "GSM based Smart home and digital notice board," in 2016 International Conference on Computational Techniques in Information and Communication Technologies, ICCTICT 2016 Proceedings, 2016.

9. D Dalwadi, N Trivedi and A Kasundra (2011), Article in Nation conference on recent trends in engineering and technology, INDI 